Published December 2019

EKONOMIKAWAN : Jurnal IImu Ekonomi dan Studi Pembangunan

ISSN : 1693-7600 (Print), ISSN : 2598-0157 (Online), http://jurnal.umsu.ac.id/indexphp/ekawan

\title{
Dari Berkebun Menjadi Entrepreneur Hingga Pelopor Opak Beras
}

\author{
Ricky Chaiyadi \\ Program Studi Bisnis, Universitas Prasetiya Mulya Jakarta, Indonesia \\ Jl. Edutown, BSD, Tangerang 15339 \\ e-mail : Chaiyadiricky@gmail.com
}

\begin{abstract}
ABSTRAK
Desa Ciputri adalah sebuah desa yang terkenal akan hasil kebun dan produk Agribisnis, terletak di Kecamatan Pacet, Cianjur, Jawa Barat, Indonesia. Mata pencaharian warga di desa tersebut mayoritas adalah bercocok tanam. Berdasarkan penelitian yang kami lakukan selama masa Community development Universitas Prasetiya Mulya, penghasilan yang didapatkan cenderung volatile. Hal ini disebabkan oleh banyak faktor seperti cuaca dan tidak adanya regulasi yang melindungi harga hasil panen. Akan tetapi, daerah Cianjur memiliki produk dengan popularitas tinggi, yaitu beras. Ibu Hani sebagai salah satu warga Sarongge, Desa Ciputri, yang juga merupakan tuan rumah yang ditunjuk untuk kelompok kami melakukan kegiatan community development dalam mengembangkan potensi yang dimiliki. Ibu Hani mengikuti program Community development dengan harapan bisa memulai bisnis dan mendapatkan penghasilan lebih yang bersifat tetap sehingga tidak hanya bergantung dengan hasil kebun saja. Indikator keberhasilan kegiatan ini yaitu perubahan pada mitra yang tidak pernah memiliki bisnis bisa menjadi seorang Entrepreneur. Ibu Hani memiliki sebuah produk kearifan lokal yaitu opak yang terbuat dari beras tumbuk Cianjur. Kelompok menilai Opak beras tersebut bisa menjadi sebuah daya tarik sebagai oleh-oleh makanan ringan khas Sarongge, Cianjur, karena rasa yang khas, nikmat, dan tahan lama serta bebas dari bahan pengawet.
\end{abstract}

Kata Kunci: Bisnis pertama, pengabdian masyarakat, Mitra, Opak Beras, Cianjur, Sarongge, entrepreneurship 


\begin{abstract}
Ciputri village is a village that's infamous for the harvest and agribusiness products, located in Kecamatan Pacet, Cianjur, West Java, Indonesia. People's main income majority is harvesting, contrary based on research that we conduct during the community development program held by Prasetiya Mulya University, the revenue that they gain is quite volatile, caused by a lot of factors such as climate and absence of regulation that can protect the price from the distributor to the gardener. Otherwise, in Cianjur area has a product with a considerably high popularity, which is the white paddy rice. Miss Hani as one of the residents in Sarongge, CIputri village, also as the host whose being chosen for our group to do community service activity in developing the potential that they have. Miss Hani joined the Community Development program in hope to start a business and earn an extra fixated revenue therefore can not only relying on the harvests result. Success indicator in this activity is the change in our partner's life who never has a business before can be an entrepreneur. Miss Hani has a indigenious product which is a rice crackers made from mashed Cianjur white rice. Our group assume that this rice cracker product can be an attractiveness as a food souvenir typically Saronge, Cianjur, emphasized by its unique flavor, delicacy, and long product lifespan also free from preservatives.
\end{abstract}

Keywords: First Business, community development, Partner, Rice Cracker, Cianjur, Sarongge, entrepreneurship.

\title{
PENDAHULUAN
}

Pembangunan perkebunan atau pertanian bertujuan untuk selalu memperbaiki mutu hidup dan kesejahteraan manusia terutama petani, baik perorangan maupun masyarakat pada umumnya (Mardikanto, 2013) seperti yang dilakukan oleh Ibu Hani sebagai salah satu warga Desa Ciputri tidak pernah menjalani kehidupan sebagai entrepreneur, mengikuti mayoritas penduduk sekitar yang menggantungkan hidupnya dari hasil kebun, sedangkan menurut Ibu Hani hal tersebut tidak cukup dan berkeinginan untuk meningkatkan taraf hidup, hal ini disebabkan oleh hasil kebun yang dinilai kurang stabil dan banyak faktor eksternal yang mempengaruhi seperti cuaca. Dari keadaan tersebut, Ibu Hani melakukan inisiatif untuk bergabung dengan program Community development yang diadakan oleh Universitas Prasetiya Mulya dan juga karena merasa ada potensi bisnis yang bisa dikembangkan bersama dengan program tersebut.

Dimulai dari Permasalahan utama yang dihadapi oleh Ibu Hani adalah kurangnya pengetahuan untuk berbisnis sehingga tidak dapat memulai sebuah bisnis atau membuat produk, hal ini disebabkan oleh karena dalam memulai sebuah bisnis diperlukan kerangka berpikir yang sistematis dan pengetahuan terkait bagaimana cara membuat sebuah produk agar usaha bisa berjalan, yang dimana belum dimiliki oleh Ibu Hani saat kami baru datang untuk menjalankan program community development bersama dengan mitra (hal ini didorong oleh keseharian ibu Hani yang hanya bekerja di kebun). 
Permasalahan kedua yang dihadapi adalah masalah geografis, yaitu letak Desa Ciputri sendiri yang sulit dijangkau dari pusat kota (butuh waktu 40 menit menggunakan transportasi angkot dengan harga $\mathrm{Rp} 25.000$,- untuk bisa pergi ke pasar Cipanas yang merupakan titik utama keramaian) medan yang curam, berbatu, sempit, dan jarak tempuh yang jauh menjadi sebuah hambatan besar bagi penduduk lokal untuk bisa meningkatkan perkembangan bisnis.

Permasalahan ketiga yang dihadapi adalah bagaimana kelompok bersama dengan Ibu Hani berusaha menemukan potensi yang dimiliki untuk bisa dijadikan usaha tetap, hal ini merupakan sebuah tantangan tersendiri bagi kelompok karena harus beradaptasi pada lingkungan yang baru, dan juga produk yang dititipkan kepada kelompok yaitu saus tomat ternyata belum pernah diproduksi oleh ibu Hani, sehingga kelompok harus mengkaji ulang dari permulaan untuk bisa mengetahui produk terbaik yang bisa dikembangkan bersama ibu Hani, dan hal tersebut menjadi tantangan terbesar yang harus dihadapi oleh kelompok adalah durasi waktu selama 22 hari.

Program Community Development sendiri yaitu sebuah program pelayanan kepada masyarakat dalam bentuk live-in dimana mahasiswa akan tinggal bersama mitra dan bersama mengembangkan bisnis dari peluang yang dimiliki oleh mitra dan kawasan yang ditempati. Kelompok kami terpilih untuk menjadi partner ibu Hani dan pada awalnya produk yang dititipkan kepada kami adalah saus tomat, setelah melalui proses identifikasi bisnis, produk saus tomat tersebut dinilai tidak feasible sehingga produk diganti dengan potensi yang kami temukan yaitu Opak beras Cianjur yang sering diproduksi oleh ibu Hani. Sehingga, program ini memiliki tujuan agar bisa mendapatkan potensi untuk dijadikan bisnis ibu Hani sehingga mitra dapat memiliki pendapatan lebih yang bersifat tetap.

\section{METODE}

Dalam menyelesaikan rumusan masalah yang ditemui oleh kelompok saat memulai kegiatan community development, kelompok melakukan beberapa pendekatan terkait 3 permasalahan tersebut, dan pendekatan itu dituangkan dalam metode penelitian kami yaitu penelitian kualitatif. Untuk penelitian kualitatif kami melakukan beberapa metode seperti in-depth interview, observasi, studi lapangan, dan juga Focus group discussion, hal ini dilakukan karena jenis masalah yang kami hadapi membutuhkan data yang bersifat pemahaman bukan sesuatu yang diukur, seperti halnya produk yang bisa dikembangkan (tidak dapat ditemukan dengan metode kuantitatif karena hasil yang ingin didapatkan merupakan hasil analisis kualitatif).

Untuk rumusan masalah yang pertama (kurangnya pengetahuan bisnis mitra), metode penelitian untuk pemecahan masalah yang kami gunakan adalah In-depth Interview atau pembahasan yang dilakukan dengan dialog antar kelompok dengan ibu Hani, diawali dengan kelompok menanyakan terkait pengalaman ibu Hani dalam dunia berbisnis, interview dilakukan di malam hari saat ibu Hani sudah selesai melakukan pekerjaan seharihari yang biasa ia lakukan, maka kelompok menyiapkan beberapa pertanyaan untuk dikembangkan lebih lanjut, namun interview berlangsung santai seperti diskusi, dan Ibu Hani sendiri bercerita terkait pertanyaan yang kami tanyakan seperti "apakah ibu pernah mencoba untuk berjualan produk?" dan ibu Hani menjawab pertanyaan tersebut sambil mengembangkan pertanyaannya. 
Untuk rumusan masalah kedua yaitu masalah geografis atau tata letak dari pusat pengembangan bisnis yaitu rumah ibu Hani dengan pusat kota atau jalur distribusi terdekat, kelompok mengidentifikasi masalah dengan metode studi lapangan. Kelompok secara langsung mencoba medan seperti mengukur berapa jarak dan waktu yang diperlukan untuk bisa mencapai pusat bisnis terdekat yaitu pasar Cipanas, transportasi apa yang tersedia, dan jalur distribusi apa yang dimiliki oleh desa Ciputri kawasan Sarongge, semua kelompok lakukan langsung dengan terjun lapangan dan studi lapangan bersama-sama mengumpulkan data dan mencoba beberapa metode.

Untuk rumusan masalah yang ketiga yaitu proses penemuan produk yang sesuai dengan potensi yang dimiliki oleh Ibu Hani, kelompok menggunakan metode observasi dan Focus Group Discussion (FGD), yang dilakukan pertama kali bersama dengan mitra kami ibu Hani yaitu memperhatikan produk keseharian yang diproduksi ibu Hani, dan melakukan FGD untuk dapat menemukan bentuk produk terbaik yang berpotensi menjadi sebuah bisnis, dan FGD juga dilakukan bersama dengan rekan-rekan yang berkunjung ke rumah seperti para Facilitator, dosen pembimbing, dan juga teman-teman community development lainnya.

\section{HASIL DAN PEMBAHASAN}

Dari ketiga rumusan masalah, metode penelitian, analisis, dan pembahasan yang telah dijabarkan pada bagian sebelumnya, hasil yang didapatkan dari proses tersebut adalah:

1. Ibu Hani mendapatkan kemampuan bisnis melebihi yang diharapkan oleh kelompok, hal ini terwujud dari beberapa bukti yaitu:

- Ibu Hani menciptakan beberapa produk baru seperti Opak beras ukuran kecil untuk segmen pasar anak-anak dan bisa menitipkan di sekolah-sekolah dan warungwarung, juga beberapa varian baru seperti kecimpring dan opak ketan hitam agar bisa menggarap pasar lebih luas lagi.

- Ibu Hani mengikuti acara-acara yang dapat menjadi media penjualan produk Opak Ashoy tanpa perlu dikoordinasi oleh kelompok terlebih dahulu.

- Ibu Hani berhasil mendapatkan logo Halal untuk produknya, yang menandakan adanya inisiatif, kesadaran, dan semangat bisnis dari dalam ibu Hani sehingga bisa mau mengikuti pelatihan tersebut tanpa perlu dipandu oleh kelompok dan mengetahui aspek-aspek penting yang diperlukan produk agar semakin memiliki nilai jual.

2. Masalah Geografis berhasil teratasi dengan adanya program bersama ibu-ibu setempat untuk menyewa angkot bersama-sama, ibu Hani membuat penjadwalan produksi bersama dengan kelompok, sehingga dengan jadwal tersebut ibu Hani bisa memaksimalkan kunjungan ke kota untuk mengecek hasil penjualan dari titipan dan juga membeli kebutuhan untuk produksi Opak Ashoy hanya dengan sekali jalan, dan dari perhitungan keuangan yang dilakukan, beban biaya dari transportasi dinilai tidak signifikan dibandingkan dengan hasil penjualan ibu Hani selama 1 bulan.

3. Produk yang dibuat bersama dengan kelompok yaitu Opak Ashoy dinilai sukses karena terbukti dari penjualan yang terus meningkat dan banyaknya pendapat bahwa produk tersebut merupakan sebuah produk baru dengan rasa yang unik namun nikmat, sehingga memiliki potensi untuk menjadi oleh-oleh khas daerah Cianjur. 


\section{Published December 2019}

EKONOMIKAWAN : Jumal IImu Ekonomi dan Studi Pembangunan

ISSN : $1693-7600$ (Print), ISSN : 2598-0157 (Online), http://jurnal.umsu.ac.id/indexphplekawan

Dari hasil yang berhasil dicapai oleh ibu Hani setelah masa live-in community development dan masa pendampingan bersama kelompok, diharapkan ibu Hani bisa tetap aktif untuk terus mengikuti kegiatan-kegiatan yang dapat menunjang usaha, dan kelompok terus membuka jalur komunikasi dengan ibu Hani agar jika ibu Hani menghadapi kendala kelompok bisa tetap mendukung proses bisnis ibu Hani agar bisa terus berkembang. Untuk produk dari Opak Ashoy sendiri, permasalahan yang masih harus dihadapi adalah masalah pemasaran yang terbatas, karena kawasan Cianjur dan Cipanas sendiri memiliki sekuensi yang tidak selalu optimal, dan turis sebagai target market utama dari produk ini, tidak selalu ada dan mau membeli produk jika bukan pada saat liburan atau ada hari istimewa, sehingga kelompok menilai ibu Hani harus mencari koneksi untuk bisa memasarkan produk lebih jauh lagi, mungkin sampai Jakarta, dan dengan bantuan gadget yang telah diberikan kelompok dan ilmu yang telah dimengerti oleh ibu Hani seperti mengoperasikan instagram, diharapkan produk ibu Hani dapat terus berkembang dan merambah pasar-pasar baru. Dengan demikian mimpi ibu Hani untuk memiliki usaha sendiri dengan penghasilan stabil serta dapat memenuhi kebutuhan keluarga dapat terwujud dan berjalan secara mandiri.

Tabel 1. Resep Opak Ashoy

\begin{tabular}{cll}
\hline No & \multicolumn{1}{c}{ Bahan Baku } & \multicolumn{1}{c}{ Jumlah } \\
\hline 1 & Beras Cianjur & 1 kilogram / produksi \\
2 & Minyak & 1 liter / produksi \\
3 & Bawang Putih dan merah & 2 siung
\end{tabular}

Sumber: kelompok B020 Community development 2019

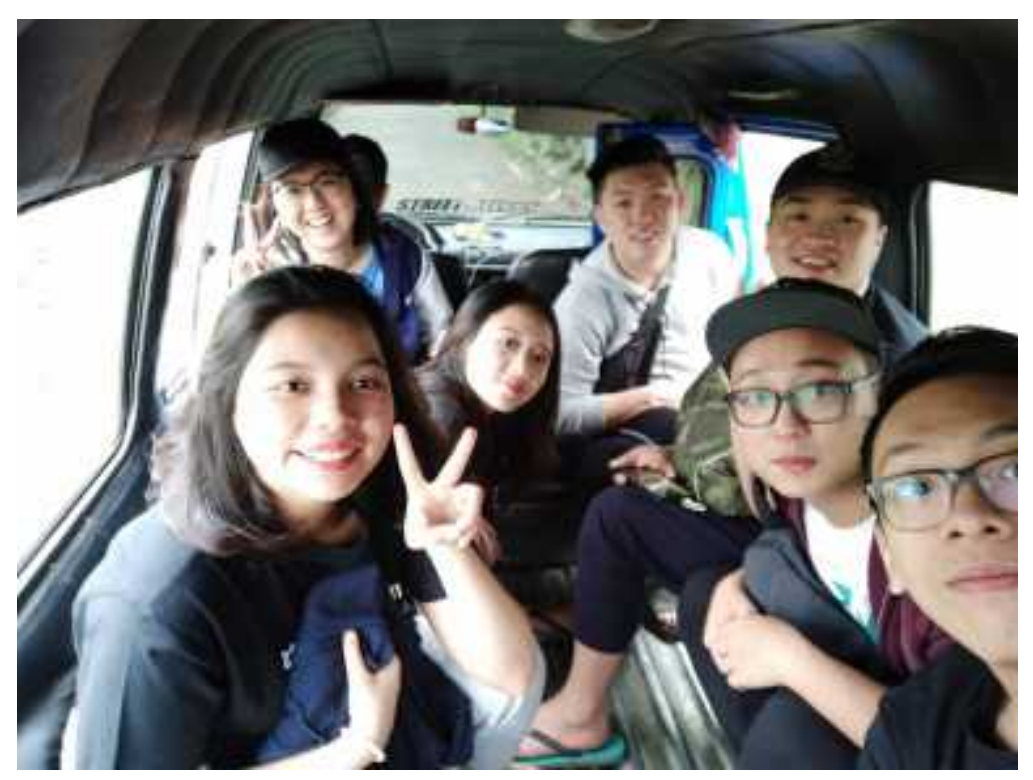

Gambar 1. Foto kelompok mencoba transportasi yang ada 
EKONOMIKAWAN : Jurnal Ilmu Ekonomi dan Studi Pembangunan

ISSN : 1693-7600 (Print), ISSN : 2598-0157 (Online), http://jurnal.umsu.ac.id/indexphp/ekawan

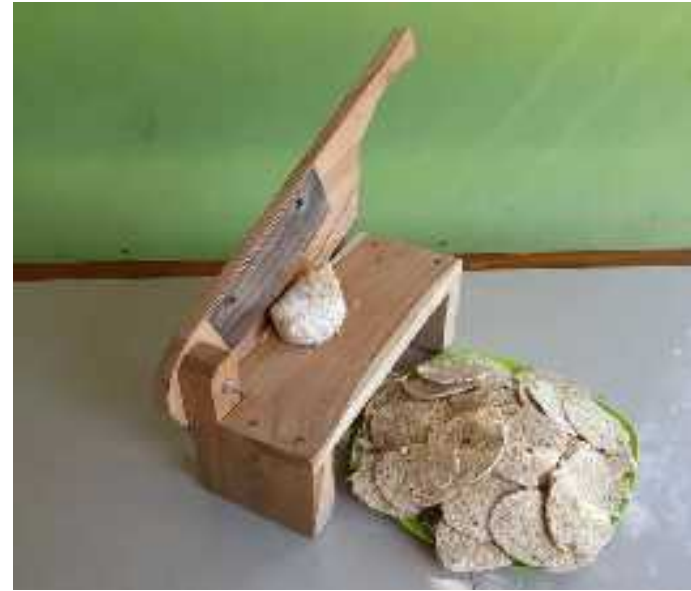

Gambar 2. Alat Pemotong

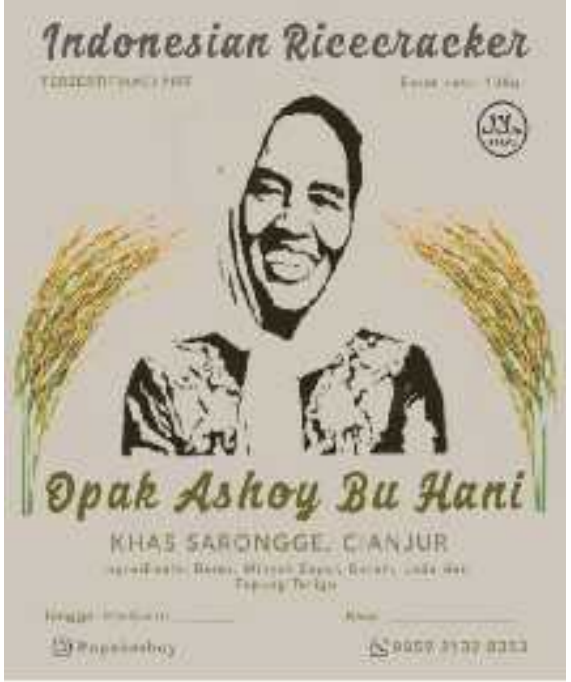

Gambar 3. Logo Produk

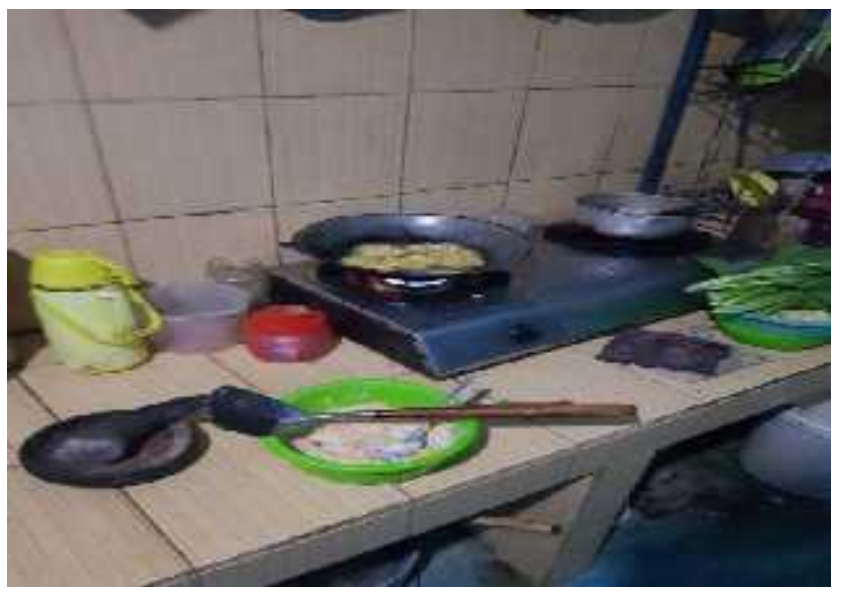

Gambar 4. Salah satu proses produksi 


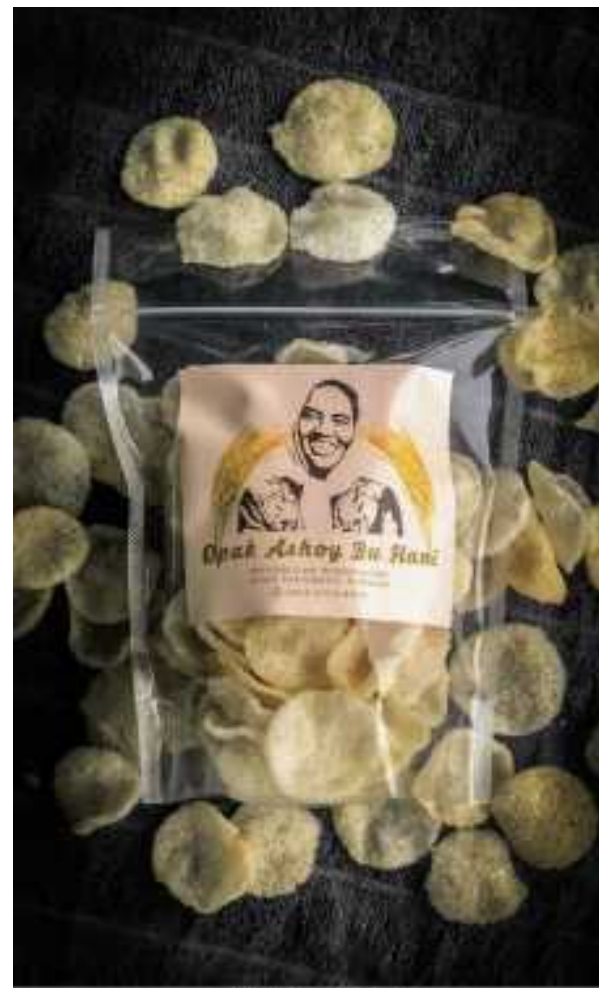

Gambar 5. Foto produk saat awal produksi

\section{Pembahasan}

Setelah melakukan analisis dengan metode penelitian yang telah kami paparkan pada salah satu bagian naskah, beberapa pembahasan terkait penyelesaian masalah tersebut adalah sebagai berikut:

- Dari Permasalahan pertama yaitu kurangnya pengetahuan ibu Hani, pertama kami mengetahui dari hasil diskusi awal dengan Ibu Hani, kami menemukan beberapa fakta seperti ibu Hani tidak memiliki handphone untuk komunikasi dan belum pernah memiliki produk atau bisnis selama ini karena ia hanya membantu di kebun milik suami, hal ini juga dibuktikan dari produk yang diajukan yaitu saus tomat, saat dibahas lebih lanjut memang produk tersebut tidak sesuai untuk Ibu Hani yang baru memulai usaha, dan keputusan Ibu Hani untuk menjadi mitra program Community Development merupakan keputusan yang tepat karena bersama kelompok ibu Hani membangun karir bisnisnya. Beberapa hal yang kelompok lakukan adalah terus mengedukasi Ibu Hani dengan pengetahuan yang sudah kami pelajari selama 5 semester di Universitas Prasetiya Mulya dan juga menyediakan beberapa fasilitas untuk keperluan berbisnis seperti gadget dan membuka rekening usaha untuk Ibu Hani, selain hal tersebut kelompok juga melakukan diskusi rutin setiap malam bersama mitra untuk menanamkan pola dan konsep berpikir untuk menjalankan sebuah bisnis. Kegiatan yang dilakukan kelompok bersama dengan mitra memiliki tujuan untuk mempersiapkan ibu Hani selaku mitra kami yang belum pernah memiliki bisnis sebelumnya untuk bisa menjalankan bisnis selama didampingi oleh kami dan agar bisa berjalan dengan mandiri setelah pendampingan kami berakhir. 


\section{Published December 2019}

EKONOMIKAWAN : Jurnal IImu Ekonomi dan Studi Pembangunan

ISSN : 1693-7600 (Print), ISSN : 2598-0157 (Online), http://jurnal.umsu.ac.id/indexphp/ekawan

- Untuk menyelesaikan permasalahan kedua yaitu masalah geografis desa Ciputri, pertama kami mengetahui dari studi lapangan seperti mencoba sendiri transportasi yang disediakan, mencoba medan dengan mencari jalan tercepat untuk mencapai pusat kota, juga mencari beberapa fasilitas atau sarana yang dimiliki oleh kawasan Desa Ciputri untuk mempermudah jalur distribusi, karena tidak dapat dipungkiri bahwa letak dan kondisi geografis dari suatu usaha dapat menjadi faktor penting dalam mengembangkan bisnis tersebut. Berdasarkan hasil studi lapangan kami, memang letak Desa Ciputri yang di atas gunung menjadi hambatan terbesar bagi bisnis mitra kami ibu Hani, salah satu transportasi yang paling memungkinkan untuk digunakan adalah angkot dan pilihan kedua adalah motor. Untuk mitra kami yaitu ibu Hani memiliki sebuah motor, namun motor tersebut sering digunakan oleh suami untuk pergi berkebun karena jarak kebun yang jauh, sehingga untuk bisa membeli motor lagi dibutuhkan modal yang besar dan hanya suami dari ibu Hani yang bisa mengendarai motor, sehingga angkot adalah satusatunya transportasi yang memungkinkan untuk ibu Hani gunakan dalam memasarkan produk dan melakukan belanja untuk produksi, yang akan tetapi harga angkot sendiri tergolong cukup mahal dengan waktu tempuh yang cukup panjang yaitu 20 menit dengan harga Rp 25.000,- untuk perjalanan pulang pergi dari rumah Ibu Hani sampai Pasar Cipanas. Kelompok kami membahas permasalahan Geografis dari usaha mitra ini dengan tujuan agar bisa membantu Ibu Hani dari jalur distribusi agar usaha dapat berkembang.

- Untuk permasalahan ketiga yaitu mencari produk yang berpotensi untuk mengganti produk saus tomat yang tidak bisa dilakukan, pertama kami mengetahui hal tersebut setelah melakukan analisa dari metode penelitian yang telah kami jabarkan yaitu melalui focus group discussion bersama ibu Hani dan beberapa ahli seperti dosen pembimbing kami dan pemimpin daerah setempat, juga melakukan observasi dari potensi lokal yang ada, maka hal yang kami lakukan yaitu melalui beberapa tahapan sebagai berikut:

1. Proses penemuan produk

Diawali dengan kelompok setelah sepakat bersama dengan mitra untuk mengganti produk, dan setelah diizinkan oleh pembimbing kami, maka metode penelitian pun dilakukan, dan kelompok melakukan observasi terkait produk apa saja yang unik dan hanya di produksi oleh ibu Hani, memiliki potensi dari segi kualitas juga memiliki mutu komersil. Hal ini termotivasi dari makanan yang disediakan oleh mitra untuk sarapan, makan siang, dan makan malam untuk kelompok, dan masakan ibu Hani sendiri selain terkenal akan kenikmatannya, namun juga sudah dibuktikan oleh kelompok potensinya.

2. Proses riset pasar produk, pemasaran dan produksi

Ketika kelompok sudah setuju akan produk yang dinilai memiliki daya jual tinggi dan bisa diproduksi oleh ibu Hani, kelompok melakukan riset pasar untuk mencari informasi terkait pesaing dari produk Opak Ashoy dan segala bahan baku yang diperlukan untuk produksi. selain mencari Supplier dan Distributor kelompok juga bersama dengan mitra melakukan produksi sampai bisa menjadikan produk akhir yang siap jual, mencarikan media penjualan, sampai mengikutkan mitra untuk melakukan beberapa pelatihan seperti PIRT (Pangan Industri Rumah Tangga / standar produk makanan). 
Untuk membuat sebuah produk pangan, diperlukan beberapa persiapan seperti pembuatan SOP (Standar Operasional Produksi) agar konsistensi produk bisa tercapai, menemukan resep yang paling tepat untuk produk. Setelah produk siap untuk dijual, kelompok membantu Ibu Hani dalam mencari media penjualan di kawasan Cianjur dan Cipanas, seperti tempat penitipan dan lokasi-lokasi untuk berjualan lainnya. Hal terakhir yang kelompok lakukan bersama dengan mitra yaitu melakukan Alpha dan Beta test, sampai pada titik produk telah disukai oleh banyak pihak maka produk akhir pun siap untuk dijual.

\section{SIMPULAN}

Melalui kegiatan Community Development yang diikuti oleh ibu Hani selaku mitra dari kelompok kami, tujuan utama dari kegiatan ini yaitu menjadikan sebuah bisnis yang sustain dan dapat memberikan pendapatan tetap untuk ibu Hani berhasil tercapai, namun setelah melalui proses tersebut kami mendapatkan pencapaian yang lebih penting dari tujuan utama kami yaitu melahirkan sebuah bisnis, yaitu terbentuknya karakter seorang Entrepreneur di dalam diri ibu Hani, terbukti dari apa yang telah kami paparkan pada bagian hasil bahwa dibutuhkan perubahan yang berasal dari dalam agar bisa memulai sebuah usaha untuk meningkatkan taraf hidup menjadi lebih baik lagi, dan diperlukan proses yang panjang untuk bisa menciptakan sebuah bisnis, yang dimana faktor utama terpenting adalah faktor sumber daya manusia yang siap untuk bisa menjalankan usaha dengan atau tanpa pendampingan.

\section{DAFTAR PUSTAKA}

Mardikanto, A. 2013, Peran Penyuluh dalam pemberdayaan petani pedesaan dan perkotaan. Jakarta. 